\title{
Dating The Ballpoint Pen Inks Using Gas Chromatography-Mass Spectrometry Technique
}

\author{
M.M.B. EL-Sabbah ${ }^{1}$, A.Z. Gomaa ${ }^{2}$, D.E. El-Hefny ${ }^{3}$ and A.S. Al-Hawary ${ }^{4^{*}}$ \\ ${ }^{1}$ Chemistry Department, Faculty of Science, Al Azhar University, Nasr City Cairo \\ Egypt \\ ${ }^{2}$ Pachin Co., Egypt. \\ ${ }^{3}$ Pesticide Residues and Environmental Pollution Department. Agricultural Research \\ Center, Dokki, Giza, Egypt. \\ ${ }^{4}$ Forensic Medicine, Ministry of Judge, Cairo, Egypt.
}

\begin{abstract}
$\mathbf{T}$ HE STUDY of aging of valuable documents is asked by the Forensic Medicine in Egypt. Eight ballpoint pens; commonly used in Egypt were chosen for this study. The aging was studied kinetically by measuring the solvent concentration of 2-phenoxyethanol overtime by the GC-MS. The ink aging curves were plotted, using the solvent volatility ratio was an effective method of determining the chronological age of the ballpoint pen inks. Our technique was demonstrated by examining two printed forms of the trust receipts. It was found that determining the ink date is valid and can be trusted. A simple equation that can be applied for the prediction of ink dating was proposed.
\end{abstract}

Keywords: Ballpoint pen ink, Questioned document, A valuable document, Ink dating, Ink aging, 2-phenoxyethanol, GC-MS.

\section{Introduction}

There are three approaches for ink dating: The first approach is the static approach; which depends on the analysis of the stable components of an ink that are specific to a particular period of time [1]. The second approach called the 'absolute dynamic approach'. This approach is based on the aging processes of ink on documents [2]. it's assumed that ink doesn't age inside the pen's cartridge [3, 4], but however only after it's placed on paper, the processes of aging like dyes fading, solvents diffusion, evaporation, and resins polymerization are started.

What is aiming to determine the relative age of ink writing to others (chronological sequence), is addressed as "relative dynamic approach" which is the third approach [2]. The comparison of the extent of ink aging may help to reconstruct the sequence of ink entries on documents. This is done if their inks are of the same formula, stored under the same conditions, and at the same type of paper as in diaries for example [5].
The most promising methods in the 1980s involved the analysis of sequential extraction of dyes using thin layer chromatography (TLC) [5-14]. Use of this method for casework was reported in the researches [12], [15], however, it had been followed by a vigorous arguing between the scientific community regarding the restrictions of this approach [8, 15-28]. Although some researchers reported the methods to be undependable [18],[24, 25, 29]; the rest scientists discussed the necessity for inter-laboratory validation before their use in casework $[17,21$ $23,26,28,30]$.

During the last decades, methods based on sequential extraction and analysis of ink volatile components by gas chromatography (GC) coupled with mass spectrometry (MS) or alternative detectors that appeared more brilliant in terms of reliability- has caught the interesting of the forensic scientists.[11, 12, 24, 30-42].

The purpose of this work is determining the

*Corresponding author e-mail: qdeahmedsoliman1@gmail.com; Mobile: 01141883500 
feasibility of the ink dating methods used as of today. For this reason; the aging processes of 2-phenoxy solvent commonly used in ink formulations were studied; eight blue ballpoint pens were selected from the Egyptian markets depending on their commonly use. Ballpoint pen inks writings were then aged for about 3 years under defined storage conditions so as to obtain an aged sample batch. Mass-spectrometric methods (GC/MS) have been tested, for the analytical characterization of ballpoint ink on documents. Measured quantities that depend on age were then defined to determine the kinetics of the reactions and produce aging curves for 2-phenoxyethanol solvents. Our technique was tested in two trust receipts commonly used in Egypt as a demonstrated example.

\section{Methods}

Substances, Materials, and Instruments used are described in Tables 1-4.

\section{Experiments}

Agilent 6890 Gas chromatograph:

The GC-MS analysis was performed with an Agilent 6890 gas chromatograph equipped with an Agilent mass spectrometric detector, with a direct capillary interface and fused silica capillary column HP-5MS (30 m X $320 \mu \mathrm{m}$ X $0.25 \mu \mathrm{m}$ film thickness). 2-phenoxyethanol samples were injected under the following conditions:

Helium was used as carrier gas at approximately $1.0 \mathrm{ml} / \mathrm{min}$., pulsed splitless mode. The time of solvent delay was $3 \mathrm{~min}$. and the amount of injection was $1.0 \mu \mathrm{l}$. The mass spectrometric detector was operated in electron impact ionization mode with an ionizing energy of 70 e.v. and using SIM mode. The ion source temperature was $230{ }^{\circ} \mathrm{C}$ and the quadruple temperature 150 ${ }^{\circ} \mathrm{C}$. The electron multiplier voltage (EM voltage) was maintained in $1050 \mathrm{v}$ above autotune. The perfluorotributylamine (PFTBA) was used to tune the instrument manually. The temperature program of $\mathrm{GC}$ was started at $90{ }^{\circ} \mathrm{C}(3 \mathrm{~min})$ then elevated to $280{ }^{\circ} \mathrm{C}$ at a rate of $8{ }^{\circ} \mathrm{C} / \mathrm{min}$. The detector and injector temperatures were set at 280 and $250{ }^{\circ} \mathrm{C}$, respectively. Wiley mass spectral database was used in the identification of the separated peaks.

\section{Samples preparation:}

Natural aging

For the natural aging study, eight blue ballpoint pens were collected from the most common types of pens in the Egyptian market used for writing purposes from libraries, as shown in Table 1. In order to study the natural aging of the ballpoint pen inks, two sets of writing samples were prepared with Arabic and English writing each week for three years on a white paper, i.e. office paper, A4 (210X297 mm) Double-A 80 GSM., multipurpose printing paper (Photocopier, Laser Printers, Fax Machine, and Ink Jet). It was taken into account that the distance between each writing was $5 \mathrm{~cm}$. The writing was done using one person's hand under a stable condition. Each sample was placed between two blank sheets of the same paper after writing the data. The first group of samples was kept in a file inside one office drawer, while the second set was left on the desktop exposed to the weather conditions, and both groups were kept in one room.

\section{Artificial aging: [34],}

Two $1 \mathrm{~cm}$ samples of the examined inks on paper are removed using a sharp scalpel. Sample 1 is placed in a vial and extracted with 10 microliters of a carbon tetrachloride $\mathrm{CCl}_{4}$ 'slowly extracting weak' solvent. 1 microliter of the extract is analyzed by GC/MS (SIM mode with detector set to monitor ions which are specific to the identified substances and internal standard).

Sample 1 is removed, dried, placed in another vial and extracted with 10 microliters of a chloroform 'fast extracting strong' solvent. 1 microliter of the extract is analyzed by GC/MS (same analysis settings). The $\mathrm{M}_{\text {weak }}$ and $\mathrm{M}_{\text {strong }}$ (mass of solvent in each extract) are figured out by means of the method of internal standard and; the solvent mass extracted percent in the weak solvent $(\mathrm{P})$ is calculated using equation 4 in Table 4. Sample 2 is then heated moderately at $70{ }^{\circ} \mathrm{C}$ and analyzed using the same procedure as for sample 1 in order to determine the percent of extraction after heating $\left(\mathrm{P}_{\mathrm{T}}\right)$.

The difference (D) between the value $\mathrm{P}$ and $\mathrm{P}_{\mathrm{T}}$ is calculated using Equation 1 in Table 4. The Drying/aging curves of pens ink strokes in term of solvent loss for 2-phenoxyethanol at $24{ }^{\circ} \mathrm{C}$ and 70 ${ }^{\circ} \mathrm{C}$ by GC/MS are plotted.

\section{Demonstration example:}

Two empty printed forms of trust receipts commonly used in Egypt were brought from the library. The first trust receipt was signed in a blank on date 26/12/2015 with the Bic ballpoint pen ink and at a later date $21 / 8 / 2016$, the data of the receipt was written with the same ballpoint pen ink. This process was done again with the 
TABLE 1. Brand of blue ballpoint pens, Note eight blue ballpoint pens were purchased in different public outlets in Egypt:

\begin{tabular}{lll}
\hline No. & \multicolumn{1}{c}{ Brand of a blue ballpoint pen } & Producer \\
\hline 1 & Bic ${ }^{\circledR}$ Cristal ${ }^{\circledR}$ Original 1.0 mm Ball pen & France \\
2 & Reynolds ${ }^{\circledR}(045$, fine carbure, medium) & France \\
3 & Parker ${ }^{\circledR}$ (Medium blue, ISO 12757-2) & United Kingdom \\
4 & Staedler ${ }^{\circledR} 430$ M (ISO 12757, Medium). & KSA \\
5 & Zebra ${ }^{\circledR}$ z-1 (Lincoln RI02865, 0.7, medium) & USA \\
6 & Uni lakubo SG-100 (Mitsubishi pencil, 0.7). & Japan \\
7 & Uni SA-S 42 (Stainless tip, medium). & Japan \\
8 & Luxor Spark- II (0.7 mm nickel Silver T.C. ball tip.) & India \\
\hline
\end{tabular}

TABLE 2. Description of different chemicals used.

\begin{tabular}{llll}
\hline No. & \multicolumn{1}{c}{ Chemicals } & \multicolumn{1}{c}{ Batch no. } & \multicolumn{1}{c}{ Producers } \\
\hline 1 & 2-phenoxyethanol $\geq 99 \%$ & 101272636 & Fluka (Sigma-Aldrich), Steinheim, Germany \\
2 & Carbon Tetrachloride & LB042307 & Lobachemie, Mumbai, India \\
3 & Chloroform & $2014 / 1$ & El Nasr Pharmaceutical Chemicals Co., Egypt \\
4 & Acetonitrile & D310271631 & Carlo Erba reagents \\
\hline
\end{tabular}

TABLE 3. Instruments used.

\begin{tabular}{lll}
\hline No. & \multicolumn{1}{c}{ Instruments } & \multicolumn{1}{c}{ Producers } \\
\hline 1 & Nikon SMZ 1000 Stereomicroscope & Japan \\
2 & VSC6000/HS (Foster and Freeman) & United Kingdom \\
3 & Docucenter 4500 and an inbuilt PIA-6000 software & Switzerland \\
4 & Agilent 6890 Gas chromatograph equipped with an Agilent mass spectrometric & The United States. \\
\hline
\end{tabular}

TABLE 4. Procedure to determine the rate of decrease of solvent extractability (D) of inks from documents described by Aginsky.

\begin{tabular}{|c|c|c|}
\hline & $\begin{array}{l}\text { Sample } 1 \\
\text { (Natural aging) }\end{array}$ & $\begin{array}{l}\text { Sample } 2 \\
\text { (Artificial aging) }\end{array}$ \\
\hline Sampling & \multicolumn{2}{|c|}{ Two $1 \mathrm{~cm}$ of the ink from the same stroke on paper } \\
\hline Treatment & No treatment & $\begin{array}{l}\text { Moderate heating } \\
\left.\text { (e.g. } 70^{\circ} \mathrm{C}, 60 \mathrm{~min}\right)\end{array}$ \\
\hline Weak extraction & \multicolumn{2}{|c|}{$10 \mu \mathrm{l}$ of an appropriate weak solvent (e.g., carbon tetrachloride) } \\
\hline Analysis 1 & \multicolumn{2}{|c|}{ Extract with acetonitrile and analyzed by GC/MS } \\
\hline Results 1 & $\mathrm{M}_{\text {weak }}=$ mass of solvent & $\mathrm{M}_{\text {weak }}=$ mass of solvent \\
\hline Strong extraction & \multirow{2}{*}{\multicolumn{2}{|c|}{$\begin{array}{l}\text { After drying, in } 10 \mu \mathrm{l} \text { of an appropriate strong solvent (e.g. chloroform) } \\
\text { extract with acetonitrile and analyzed by GC/MS }\end{array}$}} \\
\hline Analysis 2 & & \\
\hline Results 2 & $\begin{array}{l}M_{\text {strong }}=\text { mass of solvent } \\
P=100 \cdot x\left[M_{\text {weak }} /\left(M_{\text {weak }}+M_{\text {strong }}\right)\right]\end{array}$ & $\begin{array}{l}\mathrm{M}_{\text {strong }}=\text { mass of solvent } \\
\left(\mathrm{P}_{\mathrm{T}}\right)=100 \mathrm{x}\end{array}$ \\
\hline Equation I & {$[\underline{48}]$} & {$\left[\mathrm{M}_{\text {weak }} /\left(\mathrm{M}_{\text {weak }}+\mathrm{M}_{\text {strong }}\right)\right]$} \\
\hline Equation 2 & \multicolumn{2}{|l|}{$\mathrm{D}(\%)=\mathrm{P}-\mathrm{P}_{\mathrm{T}}[\underline{39}]$} \\
\hline
\end{tabular}


Reynolds ballpoint pen ink in which the signature dated on 2/12/2015 and the data on 21/8/2016 in the second receipt (Fig. 1). The value of D for both signatures and data was calculated in each receipt to determine the writing date for them and the designation of the most recent.
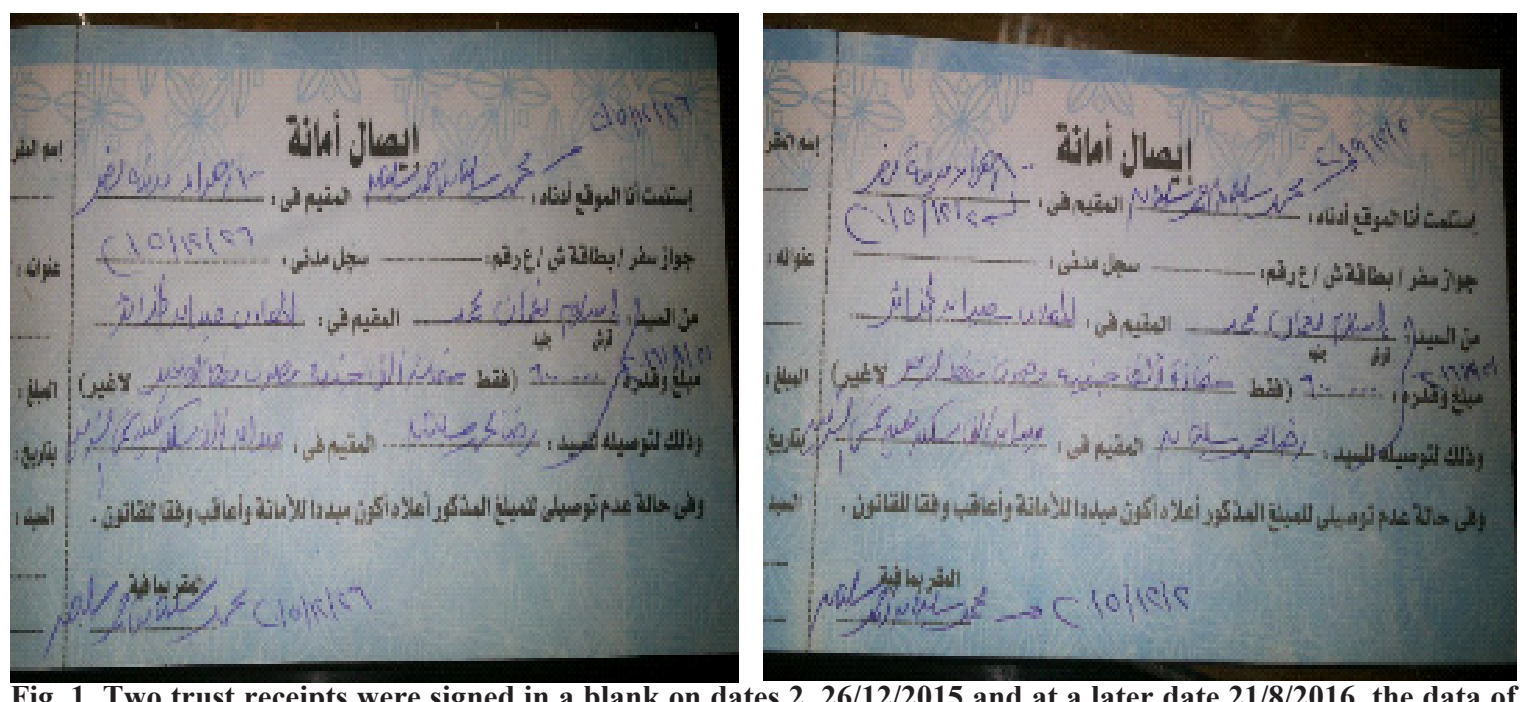

Fig. 1. Two trust receipts were signed in a blank on dates $2,26 / 12 / 2015$ and at a later date 21/8/2016, the data of the receipts were written with the same ballpoint pen ink where:

- Bic ballpoint pen

- Reynolds ballpoint pen.

The compound 2-phenoxyethanol is the most widespread solvent in ballpoint pen inks [36, 43, 44] and therefore most dating methods finally focused exclusively on the analysis of this specific substance (Fig. 2).<smiles>OCCOc1ccccc1</smiles>

$$
\begin{array}{ll}
\text { m.w. } & 138.2 \mathrm{~g} / \mathrm{mol} \\
\text { b.p. } & 247^{\circ} \mathrm{C} \\
\text { viscosity at } 25^{\circ} \mathrm{C} & 21.5 \mathrm{cP}
\end{array}
$$

Fig. 2. Structure formula, molecular weight, boiling point and viscosity of the solvent 2-phenoxyethanol.

There are many various factors that may back off or quicken the ink aging pathways and its rates [44], [45]. The examiners should be studying these parameters before determining the absolute age of the ink writing. Most of these factors are mentioned below:

\section{Ink drying principles}

One important factor that effects on the drying of the ballpoint pen inks is the evaporation of the

\section{Results and Discussions}

The eight ballpoint pens were analyzed using a GC-MS, and we found the presence of the 2-phenoxyethanol solvent that is being followed (Fig. 3), and its concentration is studied over time (up to three years). 


\section{Solvent conc. in the examind pens}

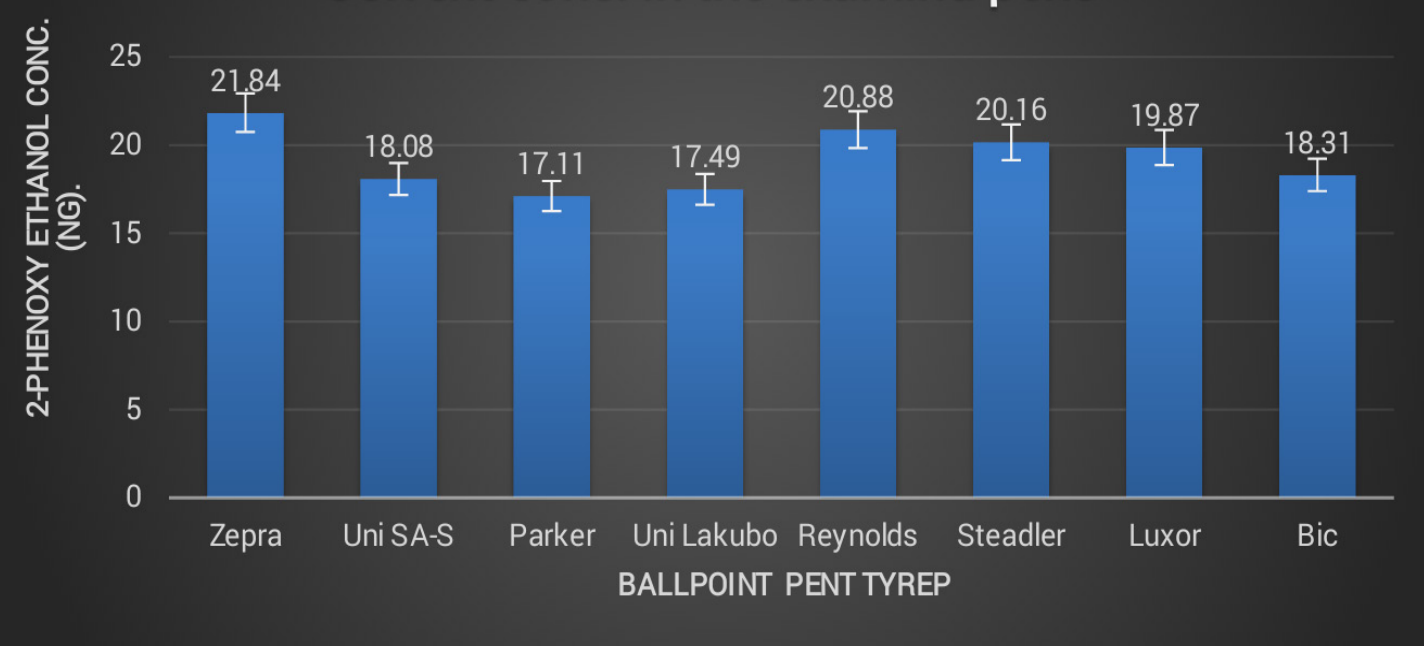

Fig. 3. Shows the primary concentrations of 2-phenoxyethanol in the studied pens.

processes happen altogether when ink is set on paper, for example, evaporation of solvents in the surrounding air, dispersion/absorption in the paper and adsorption by the paper substrate (Fig. 4). Evaporation mainly happens at the ink surface, in the paper surface close to the ink and in the paper surface at the inverse from the ink. Additionally, the molecules of solvent may diffuse into nearby surfaces (for instance in the stack of paper sheets) [39].

\section{Ink formulation}

The influence of the initial ink composition on the aging rates of inks is so vital [32], [40], and [46]. There are two aspects ought to be considered: the compounds (solvents, resins, dyes, additives) and their relative amounts (initial solvent amount among the ink formulation). Bügler et al. really suggested that the resin type influenced the aging rates as they found the presence of acetophenone-formaldehyderosin in 'slowly aging inks' [40]. It's, therefore, necessary to have definite data from the ink market

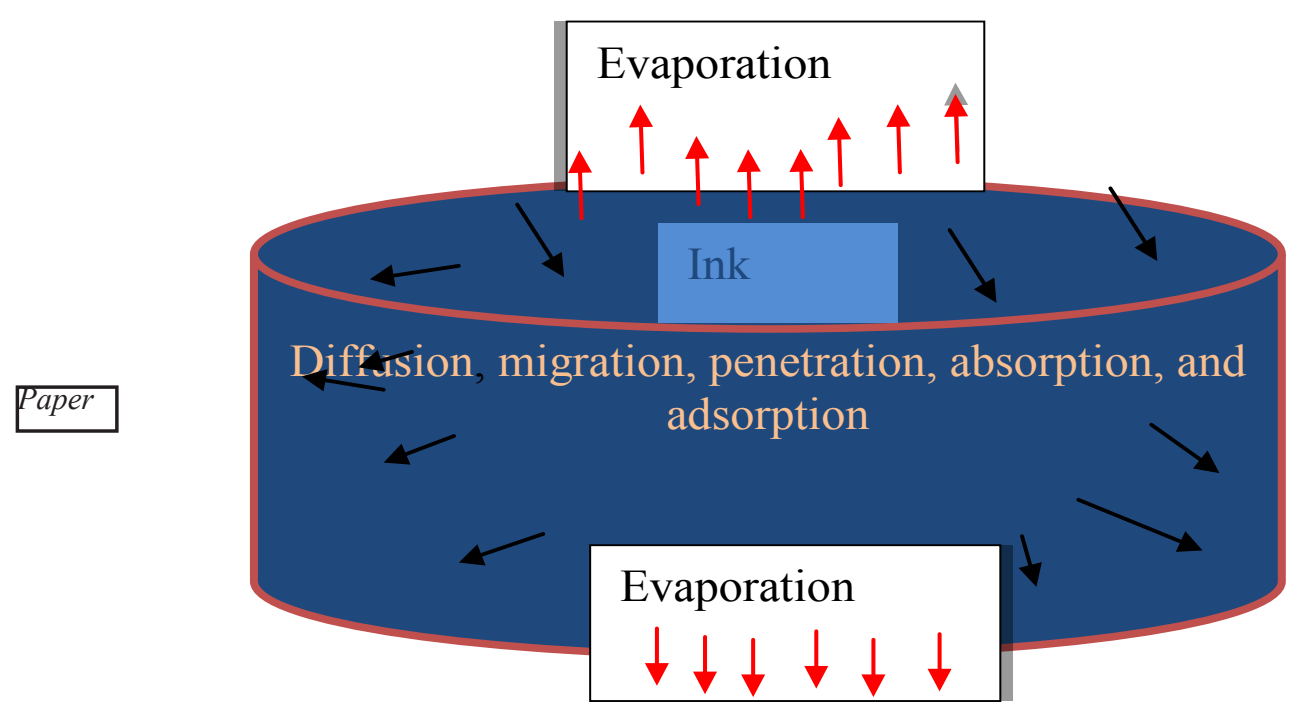

Fig. 4. Simultaneous ink drying processes on paper: the ballpoint pen solvent molecules evaporate (volatilize), diffuse (migrate and penetrate via absorption) and are adsorbed by the paper substrate. While red arrows represent evaporation, black arrows represent diffusion, migration, penetration, absorption, and adsorption. 
(for example through ink database) so as to improve the way on selected representative inks.

\section{Initial ink quantity}

The initial amount of solvents in an ink stroke influences considerably the aging method (i.e., the ink drying). For instance, the writing pressure (i.e., the thickness of ink) and/or the dimensions of the ballpoint pen's ball, should be taken into account, because of the dependence of the initial quantity of 2-phenoxyethanol solvent on them. The evaporation rate is directly proportional to the quantity of solvent. The lower the solvent's quantity on the paper, the less the evaporation rate, and therefore the greater the amount of solvent on the paper, the higher the evaporation rate.

This is problematic because the relative content of 2-phenoxyethanol varies significantly among totally different ballpoint pen inks [47] as shown in Fig. 3. The pressure applied during the writing and the size of the ball of the ballpoint pen, each of them changes the depth of the ink line and the thickness; respectively, additionally, they have an effect on the initial amount of 2-phenoxyethanol found in one $1 \mathrm{~cm}$ of ink line. Moreover, in most research works, ink entries are usually drawn as a straight line, permitting solvents to diffuse far from the stroke.

Questioned documents whether it in Arabic or another language will most probably carry texts with circle/curved lines. For example, within the letter "o" in English alphabetical and the same as in letter " $-\$$ ) in Arabic alphabetical, the solvents can diffuse to some extent far from the letter and part inside the letter s ring. Higher quantities of solvents could also be found in letters with dense

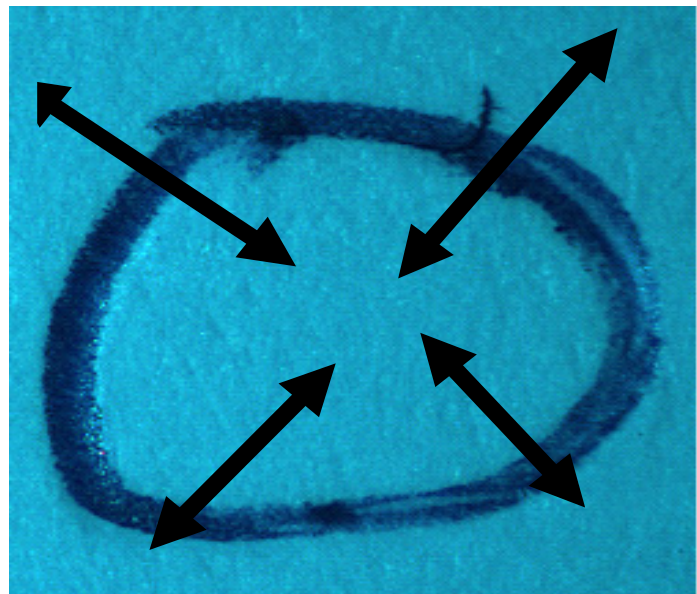

lines compared to a straight line of identical length (Fig. 5). This represents a serious drawback. Once extracting one $\mathrm{cm}$ ink lines from totally different letters, no one sure to have an equivalent solvent amount. Therefore, samples of the tested ballpoint pen inks were taken from the same letters.

In addition, consideration has been given to how to minimize this effect by calculating a mass invariant ratio between two samples; as suggested by Aginsky [34], [24]. For instance, when analyzing two $\mathrm{cm}$ in a sample, the 2-phenoxyethanol quantity will be twice the amount when analyzing one $\mathrm{cm}$ (Table 6). However, if you calculate a ratio of 2-phenoxyethanol between 2 serial extractions of an equivalent ink entry [34], [40], the ratio ought to be an equivalent no matter the length of the ink line.

Note that, the length independence between 2 samples of identical entry is only warranted, but the mass independence is not, because the density (i.e., distribution) and the pressure (i.e., thickness) vary along a stroke (Fig. 5) [40].

\section{Environmental and storage conditions}

Because of the fact that both evaporation and diffusion mechanisms play such a very important role in the drying of 2- phenoxyethanol solvent on paper (porous media), a wealth of external factors must be taken into consideration. Among these are temperature (of ink, air, and substrate), the vapor pressure of the solvent, air movement (laboratory, cabinets), humidity, the solvents' properties, and those properties of paper and ink that would make any effect on both heat transfer and mass transfer coefficients. This was confirmed by Aginsky in his research [34]. Lower temperatures and air flows

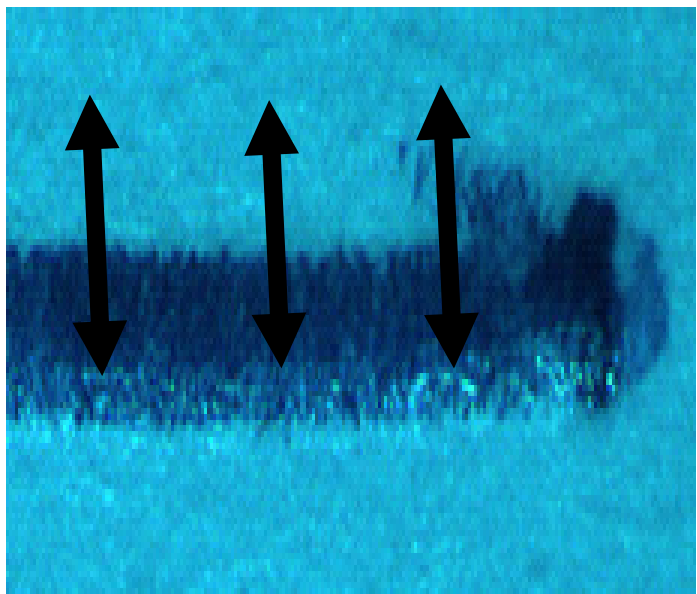

Fig. 5. Solvents diffusion from two ink entries: (right) diffusion away from a straight line, (lift) diffusion inside the loop of the letter ' 0 '. The solvent concentration may be significantly higher in $1 \mathrm{~cm}$ of the loop compared to $1 \mathrm{~cm}$ of the straight line.

Egypt. J. Chem. 62, No. 3 (2019) 
TABLE 5. Summary of $D$ threshold values defined in the literature and in conference proceedings.

\begin{tabular}{lll}
\hline $\begin{array}{l}\text { Aging } \\
\text { parameter }\end{array}$ & $\begin{array}{l}\text { Threshold } \\
\text { value }\end{array}$ & \\
\hline D\% & $>$ ca. 15 & less than 8 months \\
D\% & $<$ ca. 10 & more than 2 months \\
D\% & $>$ ca. $10<$ ca. 15 & more analyses \\
& & less than 5 months \\
D\% & $\geq 20$ & more than 6 months \\
D\% & $\leq 5$ & Less than 6 months \\
D\% & $\geq 18$ & Less than 8 months \\
D\% & $\geq 12$ & Less than 12 months \\
D\% & $>8$ & Less than 18 months \\
D\% & $\geq 6$ & Less than 24 months \\
D\% & $\geq 4$ & \\
\hline
\end{tabular}

TABLE 6. The parameters $M_{1}$ and $M_{2}$ are absolute quantities of 2-phenoxyethanol and are dependent on the length of the stroke while calculating a ratio between these two parameters yield a length independent feature.

\begin{tabular}{clll}
\hline & First parameter & Second parameter & Ration (Table 4; Equation 1) \\
\hline Ink stroke length $(\mathrm{cm})$ & $\mathrm{M}_{1}(\mathrm{ng})$ & $\mathrm{M}_{2}(\mathrm{ng})$ & $\mathrm{M}_{1} \mathrm{x} 100 /\left(\mathrm{M}_{1}+\mathrm{M}_{2}\right)$ \\
& 20 & 40 & 33.3 \\
1 & 40 & 80 & 33.3 \\
\hline
\end{tabular}

will slow down the drying process. Moreover, room temperatures may vary considerably between summer and winter (except for airconditioned rooms), whereas humidity is rarely constant even in an air-conditioned environment.

Fresh strokes on adjacent sheets of paper should be taken into consideration, because the fresh strokes' solvent may migrate to the old strokes [33, 39, 44, 48]. It had been found that the quantities of the concerned solvent during the migration of fresh stroke (has zero time age) exceeded those found in a stroke has two weeks age [39], so migration to a stroke should be taken into consideration for the dating of ink entries by solvents quantification. The paper blank analysis can facilitate reducing the risk [32]. Because the diffusion of solvents from the ink stroke into the paper, the paper blank mustn't be sampled too near to the writing ink [39].

To determine the eight ballpoint pen inks under the study; we should follow what Aginsky summarized (Table 5) in his literature [34] as follow:

- If the D value is equal to ca. $15 \%$ or higher, the natural aging of the strokes' ink has not stopped until the moment of analysis, i.e., the entry is recent, less than 8 months. e.g. by over a year preceding the analysis, the examiner can state with confidence that this document has been backdated.

- If the D value is less than ca. $10 \%$ - It suggests that the questioned entry's age is larger than two months, on condition that the questioned writing has been stored under normal conditions of temperature, light, and constant humidity.

It should be taken into account, that such results can also mean that the binder of the questioned entry's ink is not capable of polymerization or any different mechanism of solidification as a function of aging, but this case is happened rarely due to very few such inks on the market.

- If the D value is higher than ca. $10 \%$ and less than ca. $15 \%$; further samples should be taken to ascertain the values of $\mathrm{D}$ are nearer to $10 \%$ or $15 \%$; then the conclusion should be taken with a particular degree of confidence.

There are at least two possibilities mentioned Egypt. J. Chem. 62, No. 3 (2019) 
in [34]; to narrow the interval comprising the real age of ink in the questioned entry:

(1) The formula of the ink is known and reference samples could be prepared;

(2) Determination further thresholds should be done as follows;

- If the $\mathrm{D}$ value is equal to or higher than ca. $20 \%$; the ink sample is less than five months.

- $\quad$ If the D value is equal to or less than ca. $5 \%$; the ink sample is older than six months

In a conference was held in 2002 [32]; new values for $\mathrm{D}$ are presented in Table 4 to determine the entry of ink has not stopped yet.

The principle follows the idea that, when the ink is old, $\mathrm{P}$ is low and $\mathrm{P}_{\mathrm{T}}$ is also low (then the difference $\mathrm{D}$ is low and the rate of sample drying decreased). When ink is fresh, $\mathrm{P}$ is high and $\mathrm{P}_{\mathrm{T}}$ is lower (then the difference D is high and the sample is still drying) (Fig. 6).

The presence of a high quantity of 2-phenoxyethanol or the finding of a high aging parameter may indicate a fresh ink, whereas its absence does not allow any conclusion about the age [40].

Figure 7 represents the drying/aging curve of pens ink strokes in term of solvent loss for 2-phenoxyethanol at both $24{ }^{\circ} \mathrm{C}$ and $70{ }^{\circ} \mathrm{C}$ by GC/MS. This experimental result characterizing the mechanism of evaporating the volatile component 2-phenoxyethanol from aging inks. It can be interpreted as follows. The process of such evaporation is carried out from the surface of the ink line placed on a paper. To reach the ink line surface a vehicle must diffuse from the inner layers of the line. However, resins and other viscous ballpoint ink ingredient limit a diffusion process (to some extent, of course). In addition, as soon as the reaction of cross-linking or polymerization of these ingredients has started, those diffusion processes are getting more slower, and at a certain stage of ink aging they stop completely ' keeping" the remained micro drops of the ink volatile components inside the aging ink line for a practically infinite period of time) or until extracting by a solvent or heating "frees" them).

So when using a strong solvent capable to dissolve hardened ink resins like chloroform, those vehicle remainders can be easily detected even in very old ballpoint ink writings. The different situation takes place when a "weak" (with regard to hardened ink resins) solvent is used. It cannot penetrate into an old ink line, so it extracts ink volatile components only from outside layers of the ink line. But the newer the ink, the more outside ink layers (up to the whole ink material for fresh inks) become available for the weak solvent, and hence, the more quantity of volatile components is extracted.

Returning to Fig. 6 one can see that the above-considered tendency, indeed, characterizes the behavior of a weak solvent: the extracting efficiency of carbon tetrachloride decreased from

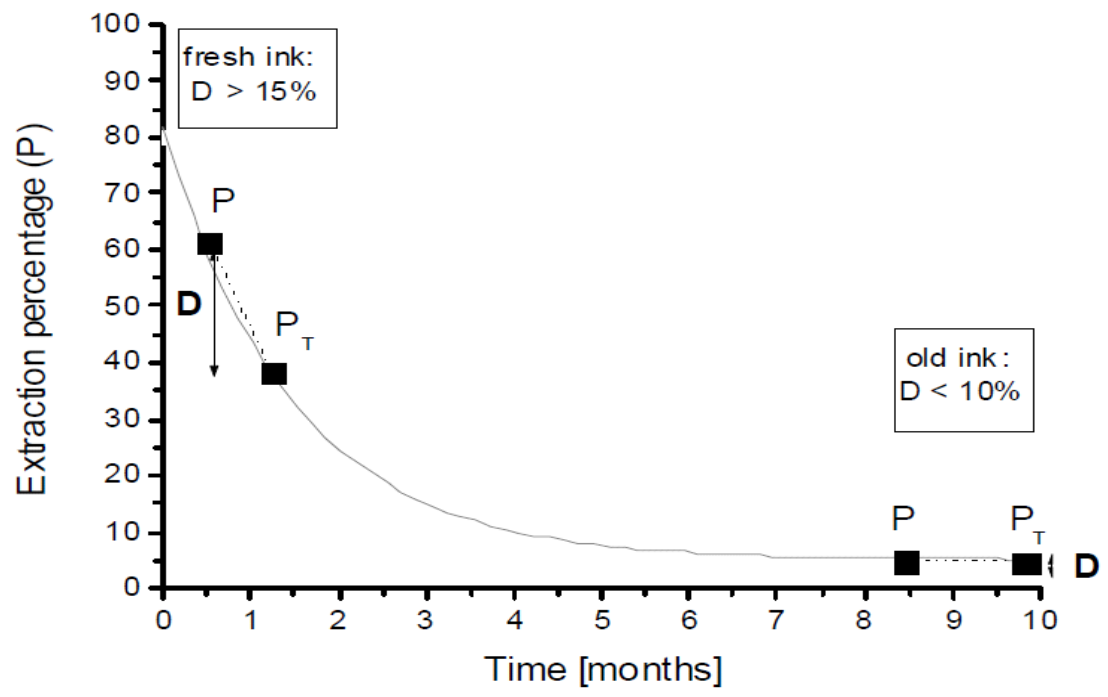

Fig. 6. Graphical presentation of the threshold values proposed by Aginsky in 1996 [29] to determine a time frame within which a questioned entry has been actually written.

Egypt. J. Chem. 62, No. 3 (2019) 
A

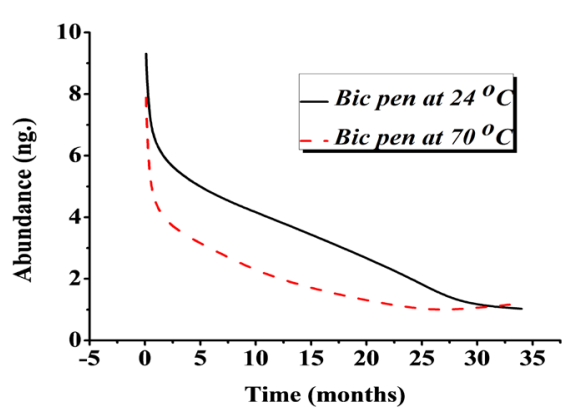

C

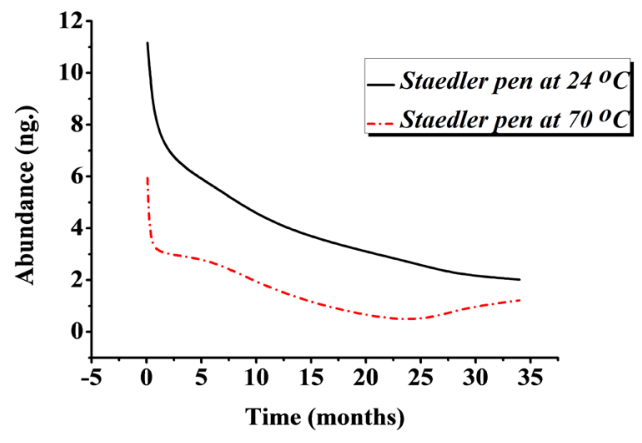

$\mathbf{E}$

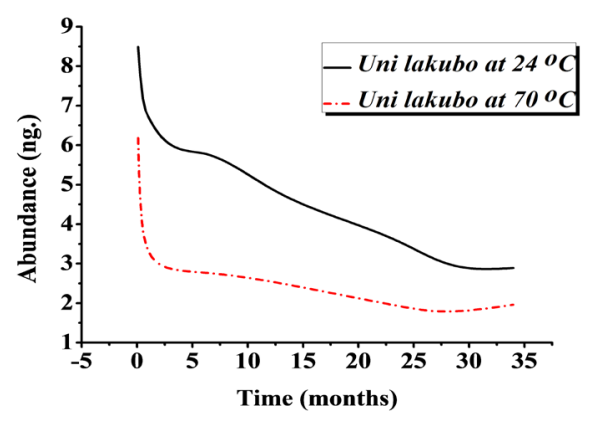

G

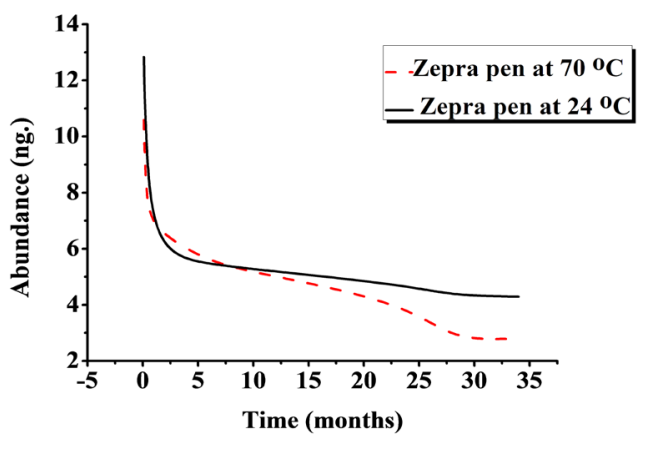

B

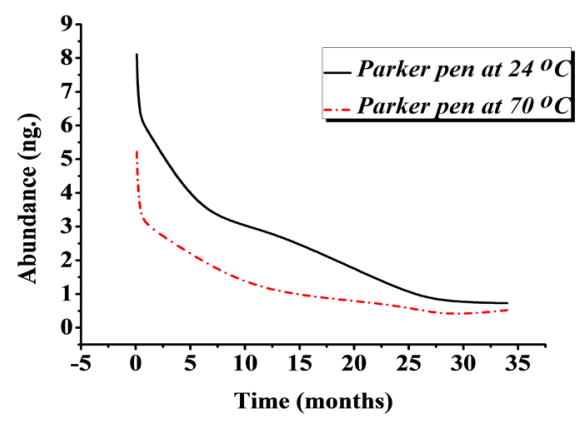

D

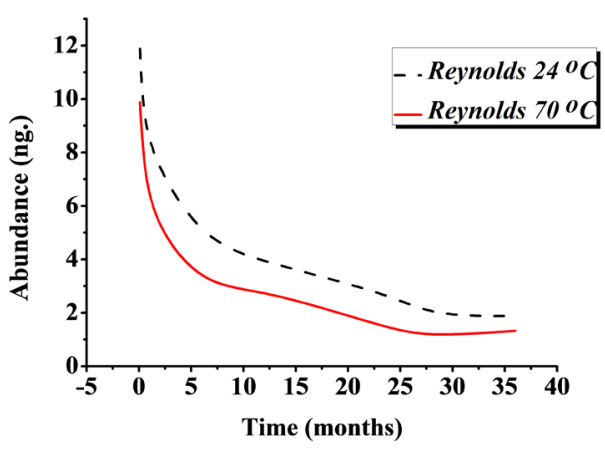

F

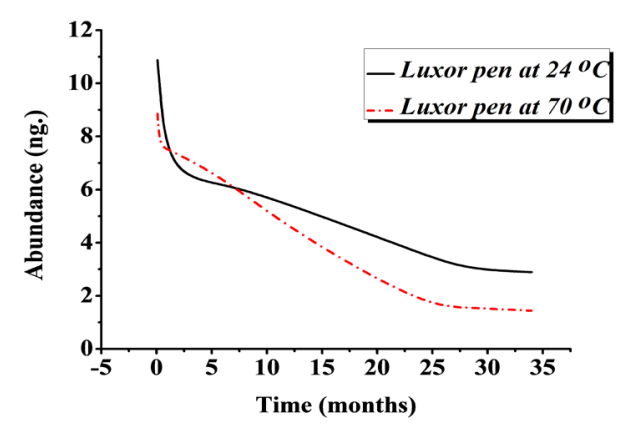

H

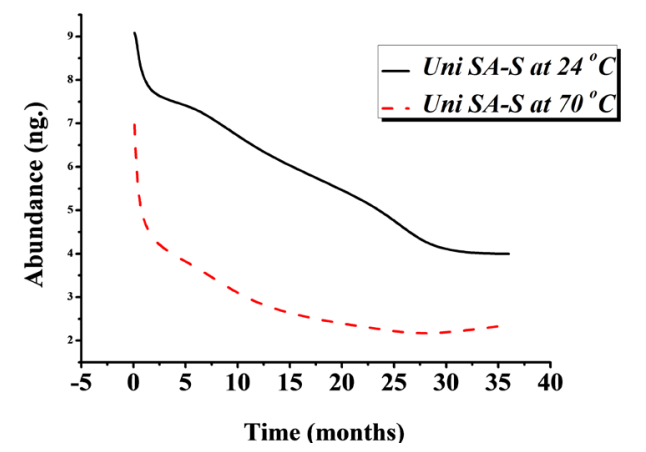

Fig. 7. Drying/aging curve of pens ink strokes in term of solvent loss for 2-phenoxyethanol at $24^{\circ} \mathrm{C}$ and $70{ }^{\circ} \mathrm{C}$ by GC/MS where: Bic, (B) Parker, (C) Staedler, (D) Reynolds , (E) Uni lakubo, (F) Luxor, (G) Zebra, and (H) Uni SA-S. 
about $90 \%$ (fresh writings) to about $20 \%$ (old writings).

The proposed method has shown good efficiency for dating the ballpoint inks which contained 2-phenoxyethanol (a comparatively high boiling vehicle that boils higher than $200^{\circ} \mathrm{C}$ ). At the same time, when using this technique one should remember that samples of approximately equal thickness (depth) of ink line are to be taken from questioned and known ink entries. It seems quite obvious because of thicker lines "store" The volatile components may be the thinners in the formulation of the ink.

Docucenter Video spectral analysis is performed with equipment that uses a charge coupled device (CCD) to acquire an image of a document from a stage. The image is projected onto a monitor. There are many illumination and filtering devices reveal differences in infrared absorption, transmittance, and luminescence and UV wave excitation of visible luminescence (fluorescence) of ink.

Video spectral analysis provides one advantage over all other types of ink analyses: It permits a quick examination of the entire questioned document and may reveal ink similarities in context, or difference in chemical formulation.

The inks of the ballpoint pens (Reynolds and Bic), in which the data and signatures of the two trust receipts were written (Fig. 1) - were examined by means of the usual "non-destructive" technical inspection (Docucenter Table 3) under different infrared (630 to $780 \mathrm{~nm}$ ) and ultraviolet rays (254, $365)$, hoping to reach a difference between any of the signatures or data, due to the different date between them (Fig. 7 and 8). We did not obtain any positive results for the estimating absolute or at least the relative aging neither for the data or signatures as shown in Fig. 7 and 8.

Therefore, we conducted the examination using the suggested method (destructive), and we got a positive result. The value of the $\mathrm{D}$ for the trust receipt's data written with the Reynolds ballpoint pen dated on 24/8/2016 equals 27.3 while the $\mathrm{D}$ value for the signature which written with the same ballpoint pen ink on $2 / 12 / 2015$ equals 4.3 (Fig. 9).

For the other trust receipt, which written with the Bic ballpoint pen and its data dated on August 21,2016 , and the signature on 20/12/2015; the D values for the data and the sign were equal to 22.3 and 3.6, respectively (Fig. 9). Which indicates that the dates of writing the signatures in both receipts are prior to the date of writing the data, i.e. that each receipt has been signed on the blank.

Although the initial value of phenoxyethanol was different in both ballpoint pens, as shown in Fig. 3, the current method was able to determine the chronological age of each.

We are able to determine the time period of the data and signatures, hence; we proved that the signatures were written at the time prior to the data, i.e., the trust receipts were signed in a blank.

Concentration - Dating Time Equation (CDTE)

From the previous results, we tried to reach to a simple equation which can be used for the prediction of the approximate ink dating of the document. In order to achieve this equation, we have to know the exact concentration of the used solvent (2-phenoxyethanol) and the type of pen.

The results of GC/MS are used for the relation between the concentration of 2-phenoxyethanol and Logarithmic scale of time (days) at 24 and $70{ }^{\circ} \mathrm{C}$. This relation was demonstrated in straight lines proving the relationship (CDTE);

$\mathrm{C}=\mathrm{a}+\mathrm{b} \log \mathrm{t}$

Where:

$\mathrm{C}$ : concentrations of the used solvent (2-phenoxyethanol),

t: time (days), “ink dating"

$\mathrm{a}$ : (intercept) and $\mathrm{b}$ :(slope) are constants depending on the type of pen.

However, if we cannot know the type of ballpoint pen, in this case, we can use the average values for $\mathrm{a}$ and $\mathrm{b}$ for the eight ballpoint pens which gives the approximate results as we see in the following equation:

$\mathrm{C}=11.4-2.91 \log \mathrm{t}\left(\right.$ at $\left.24{ }^{\circ} \mathrm{C}\right)$

On the other hand, as we look at the values of $\mathrm{R}^{2}$ linear regression, we will find that calculations of the dating time at $24^{\circ} \mathrm{C}$ is more accurate than $70^{\circ} \mathrm{C}$.

\section{Demonstration Example:}

If we are selecting the dating time $(3,180$ and 840) for Bic and Reynolds ballpoint pens which are the most common pens in Egypt, and try to check between ink dating and real calculated values for Equation 2, We have reached that the 


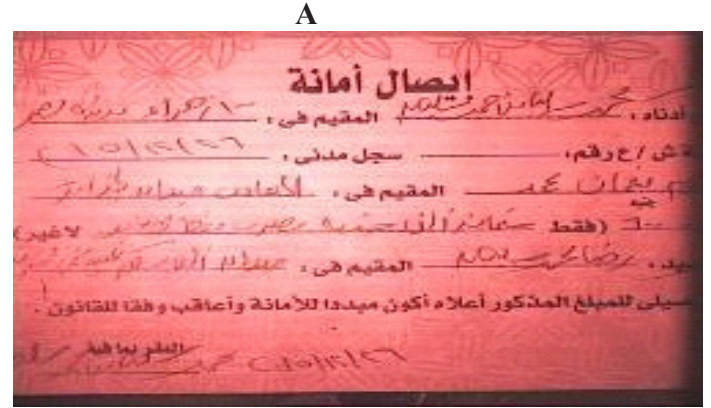

C

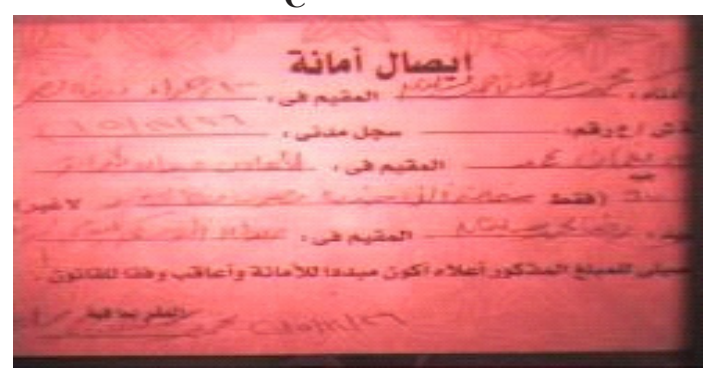

$\mathbf{E}$

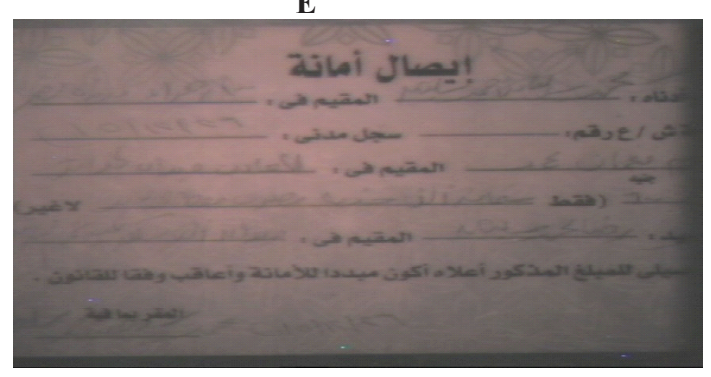

G

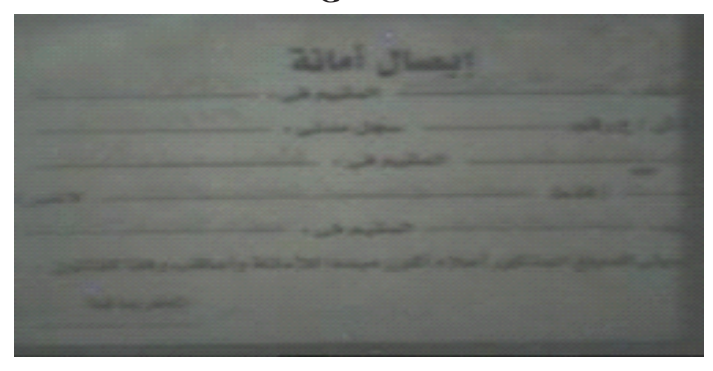

I

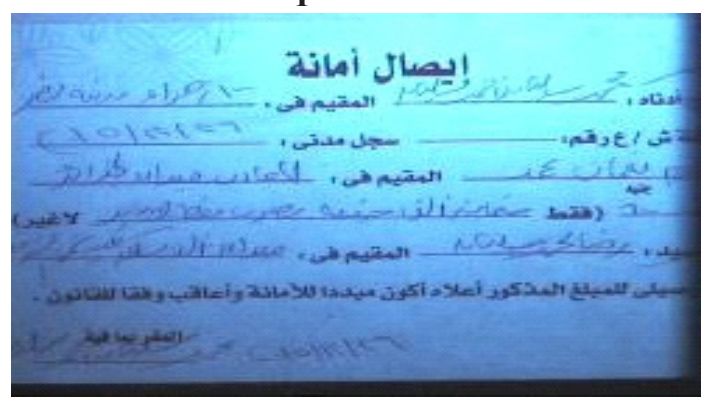

B

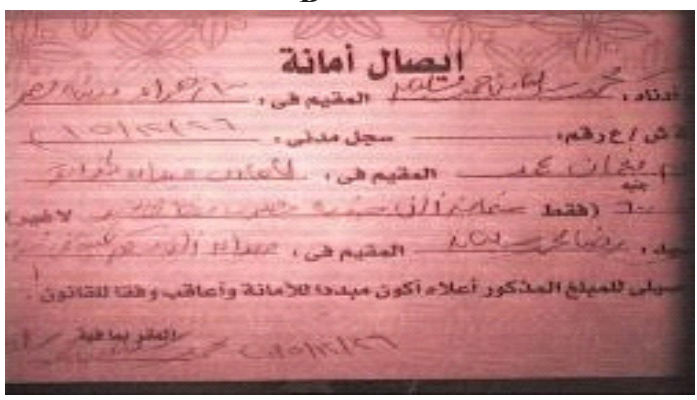

D

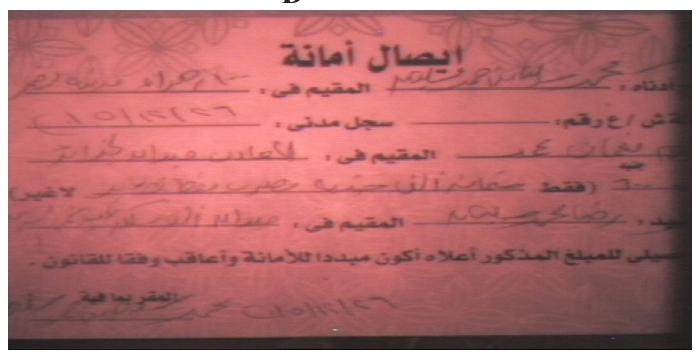

F

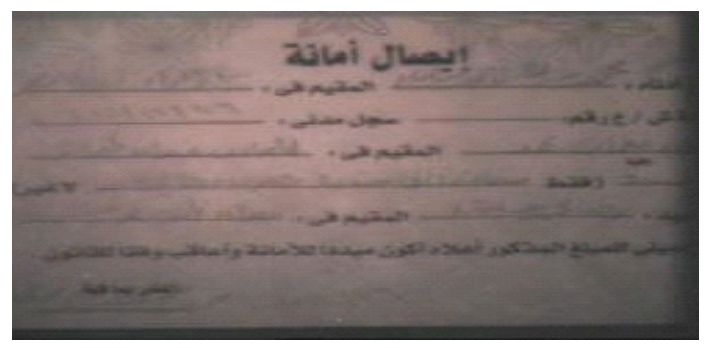

$\mathbf{H}$

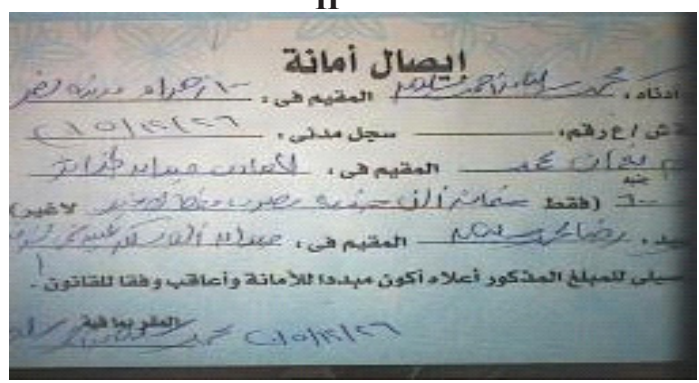

$\mathbf{J}$

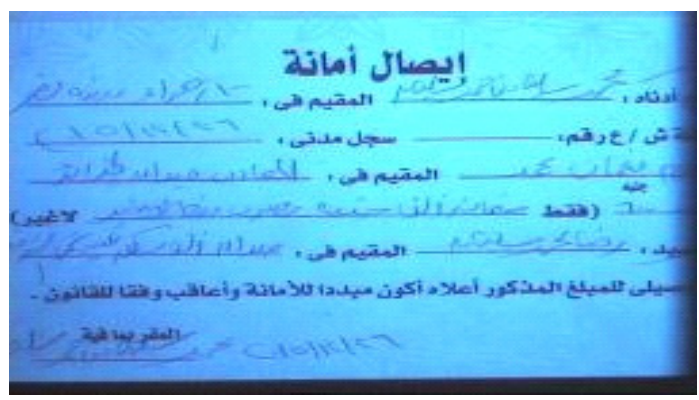

Fig. 8 . The trust receipt which was written with the Bic ballpoint pen under different wavebands where; $630 \mathrm{~nm}$., (B) $645 \mathrm{~nm}$, (C) $665 \mathrm{~nm}$, (D) $695 \mathrm{~nm}$, (E) $715 \mathrm{~nm}$, (F) $735 \mathrm{~nm}$, (G) $780 \mathrm{~nm}$, (H) No filter (I) $254 \mathrm{~nm}$, (G) $365 \mathrm{~nm}$.

No differentiation has been found between the data and the signature

Egypt. J. Chem. 62, No. 3 (2019) 
A

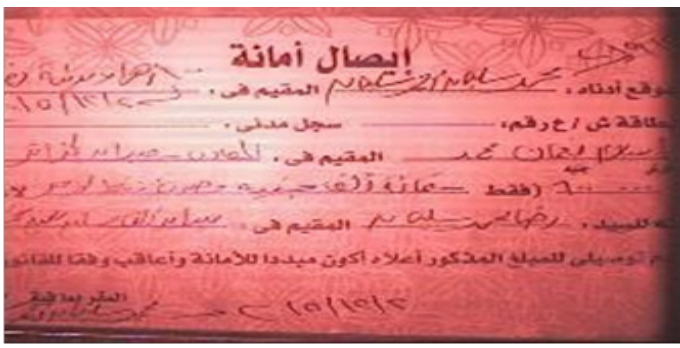

C

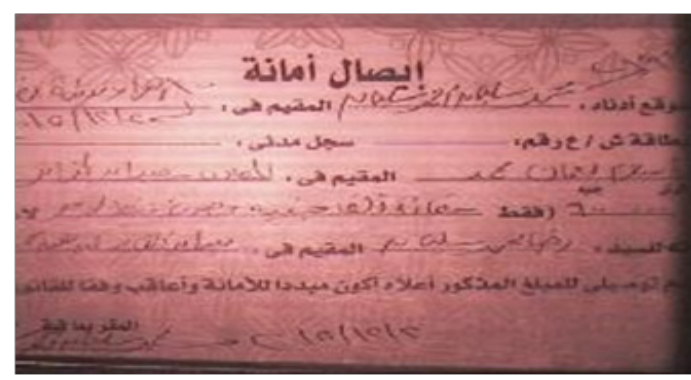

E

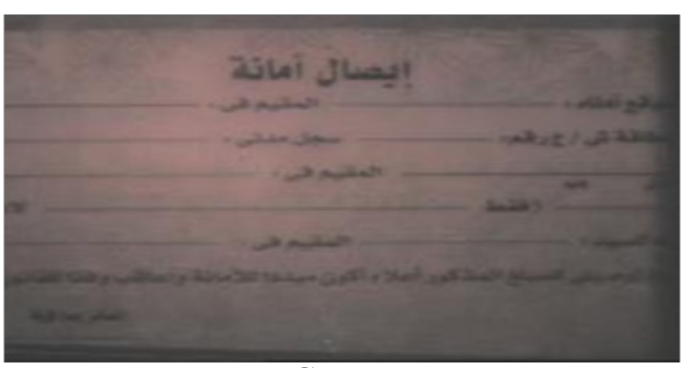

G
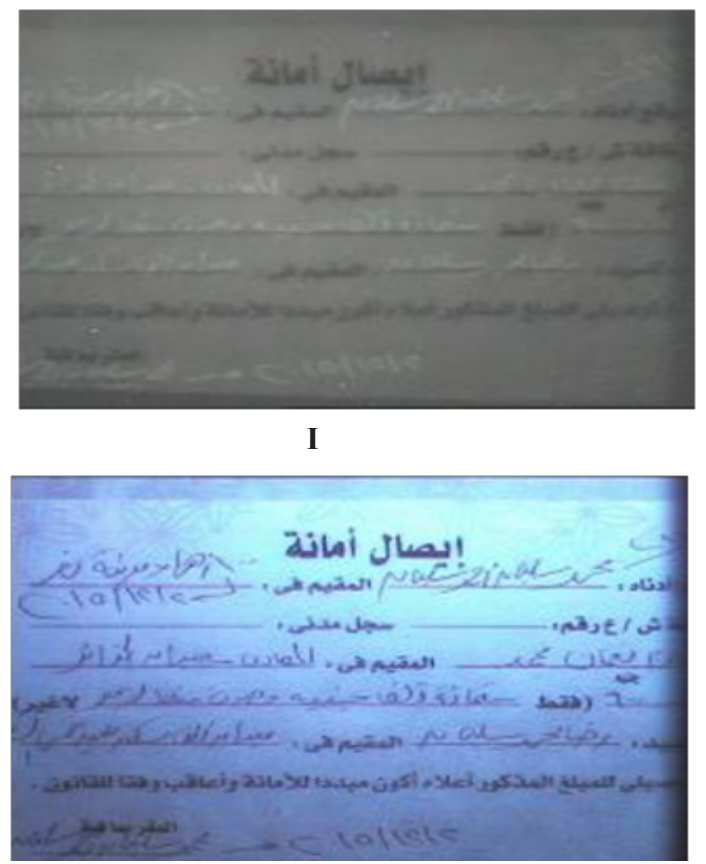

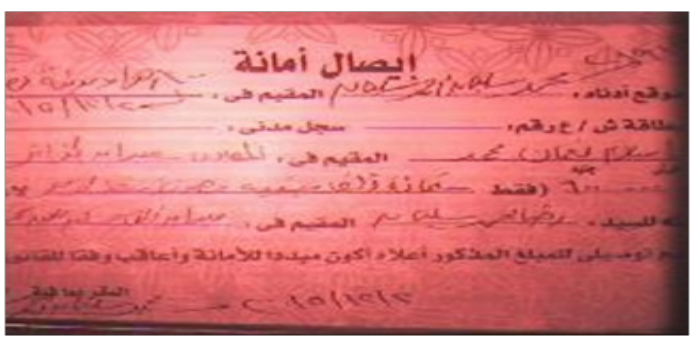

D
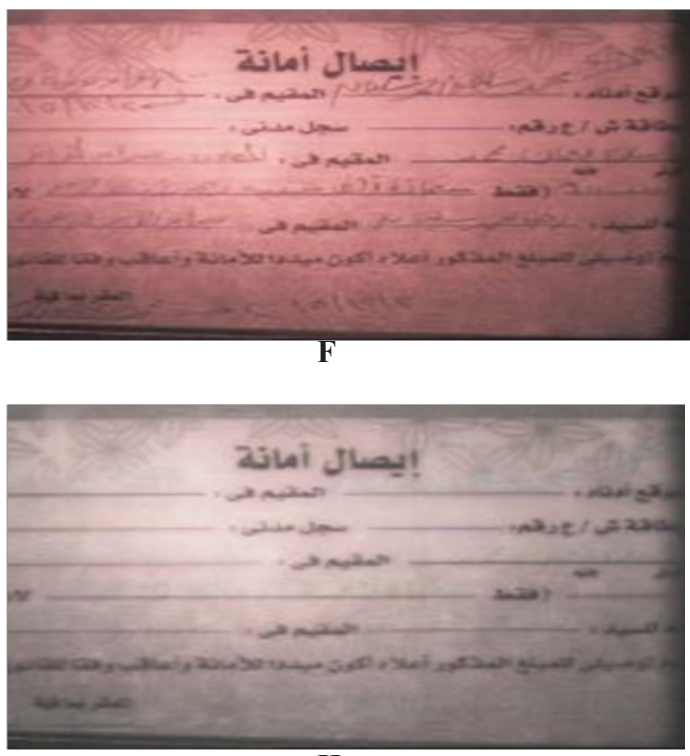

H

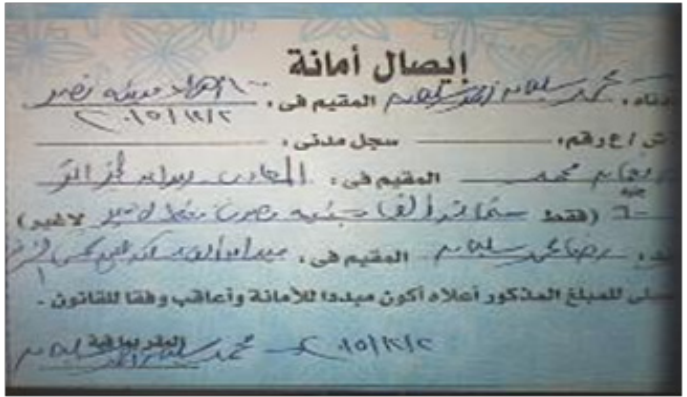

J

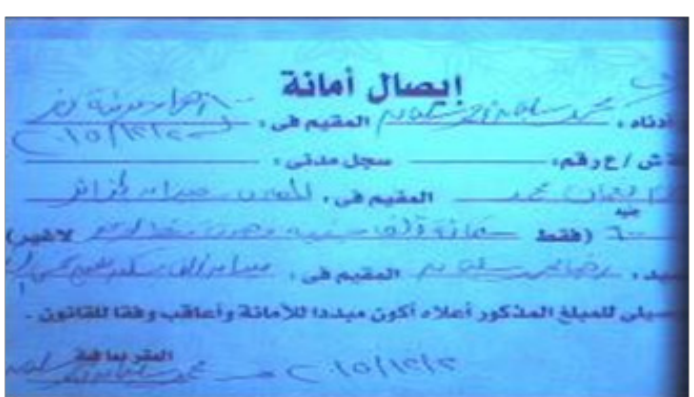

Fig. 9. The trust receipt which was written with the Reynolds ballpoint pen under different wavebands where; (A) $630 \mathrm{~nm}$., (B) $645 \mathrm{~nm}$, (C) $665 \mathrm{~nm}$, (D) $695 \mathrm{~nm}$, (E) $715 \mathrm{~nm}$, (F) $735 \mathrm{~nm}$, (G) $780 \mathrm{~nm}$, (H) No filter (I) 254 $\mathrm{nm}$, (G) $365 \mathrm{~nm}$.

No differentiation has been found between the data and the signature.

Egypt. J. Chem. 62, No. 3 (2019) 


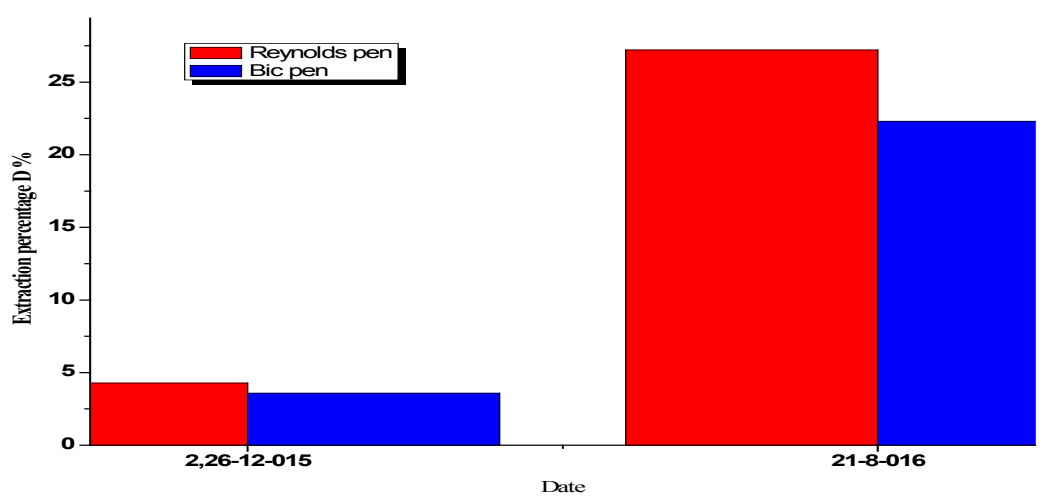

Fig. 10. Graphical presentation of the threshold values to determine a time frame within which a questioned entry has been actually written, where a fresh ink has D values higher than $15 \%$ and an old ink has D values less than $10 \%$
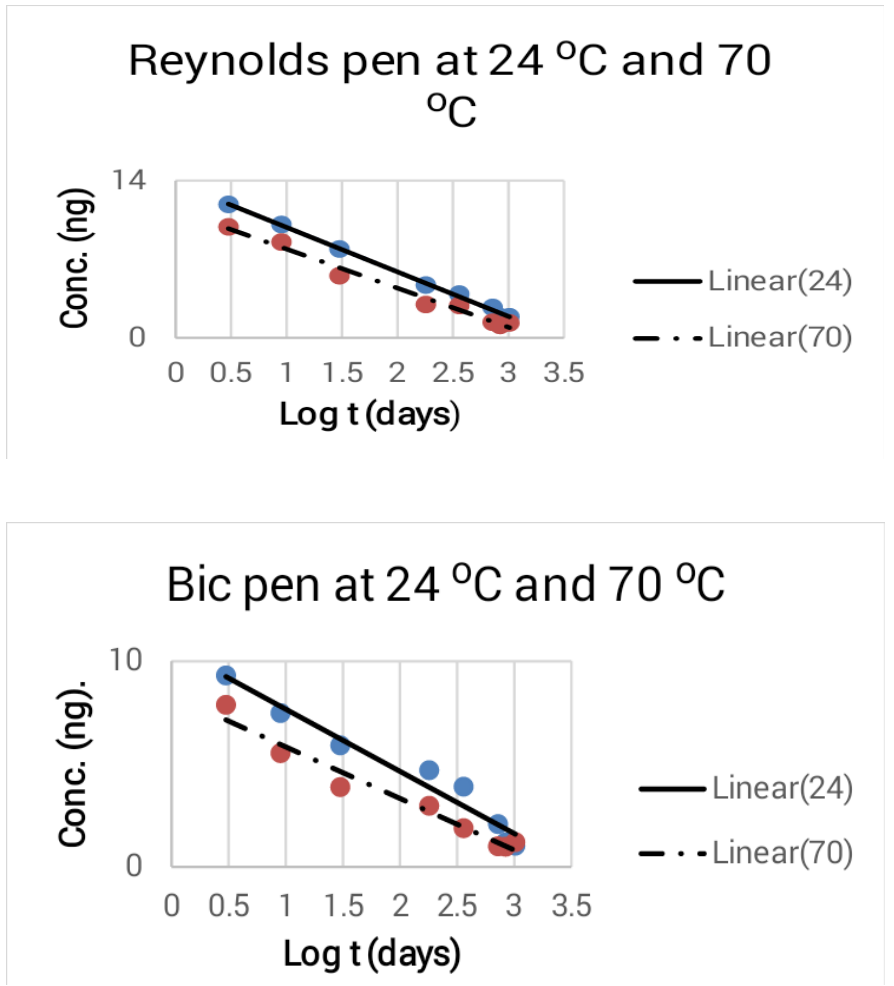

Fig. 11. The relationship between the solvent concentration of 2- phenoxyethanol and dating time for the Reynolds and Bic ballpoint pens as a sample.

tolerance period ranging from $(3$ and $\approx 11 \%$ ) for ink dating and real calculated values (Table 7). From this, we arrive at the fact that this equation can be safely used.

\section{Conclusion}

The results of the proposed method used to study the evaporation of solvent 2-phenoxyethanol over time from the ballpoint pen inks under the study have resulted in their ability to determine the chronological age of the ballpoint pen inks. Therefore, it can be relied upon to estimate the aging of the valuable documents written in such ballpoint pen inks. It is noteworthy 
to mention that using other methods like IR, transmittance, luminescence and UV excitation are not promising. From our results, we reached to a simple equation which can be used for the prediction of the approximated ink dating of the document.

\section{References}

1. Cantu, A.A., A sketch of analytical methods for document dating. Part I. The static approach: determining age independent analytical profiles. International Journal of Forensic Document Examiners, 1(1), 40-51 (1995).

2. Cantu, A.A., A sketch of analytical methods for document dating. Part II. The dynamic approach: determining age-dependent analytical profiles. International Journal of Forensic Document Examiners, 2(3), p. 192-208 (1996).

3. Andrasko, J. and M. Kunicki, Inhomogeneity and aging of ballpoint pen inks inside of pen cartridges. Journal of Forensic Science, 50(3), 1-6 (2005).

4. Grim, D.M., J. Siegel, and J. Allison Does ink age inside of a pen cartridge? Journal of Forensic Science, 47(6), 1294-1297 (2002).

5. Cantu, A.A. and R.S. Prough, On the relative aging of ink - the solvent extraction technique. Journal of Forensic Science, 32(5), 1151-1174 (1987).

6. Cantu, A., Comments on the accelerated aging of ink. Journal of Forensic Science, 33(3), 744-750 (1988).

7. Brunelle, R.L., A sequential multiple approaches to determining the relative age of writing inks. International Journal of Forensic Document Examiners, 1(2), 94-98 (1995).

8. Brunelle, R.L., C. Breedlove, and C.R. Midkiff, Determining the relative age of ballpoint inks using a single-solvent extraction technique. Journal of Forensic Science, 32(6), 1511-1521 (1987).

9. Brunelle, R.L. and K.R. Crawford, Advances in The Forensic Analysis and Dating of Writing Ink: Charles C Thomas Publisher, (2003).

10. Brunelle, R.L. and H. Lee, Determining the relative age of ballpoint ink using a single-solvent extraction, mass-independent approach. Journal of Forensic Science, 34(5), 1166-1182 (1989).

11. Aginsky, V.N., Some new ideas for dating ballpoint inks - a feasibility study. Journal of Forensic Science, 38(5), 1134-1150 (1993).

12. Aginsky, V.N., Determination of the age of ballpoint pen ink by gas and densitometric thinlayer chromatography. Journal of Chromatography A, 678(1), 119-125 (1994).
13. Aginsky, V.N., A microspectrophotometric method for dating ballpoint inks - a feasibility study. Journal of Forensic Science, 40(3), 475478 (1995).

14. Stewart, L. and S. Guertin, Current status of ink age determination. International Criminal Police Review, 429, 9-12 (1991).

15. Brunelle, R.L. and E.J. Speckin, A technical report with case studies on the accelerated aging of ballpoint inks. International Journal of Forensic Document Examiners, 4, 240-254 (1998).

16. Brunelle, R. and A. Cantu, A critical evaluation of current ink dating techniques. Journal of Forensic Science, 32(6), 1522-1536 (1987).

17. Brunelle, R. and A. Cantu, Training requirements and ethical responsibilities of forensic scientists performing ink dating examinations. Journal of Forensic Sciences, 32(6), 1502-1506 (1987).

18. Lyter, A. Relative aging of ball pen ink: natural aging vs. artificial aging in American Academy of Forensic Sciences Meeting, San Antonio, TX. (1994).

19. Champod, T.H., A. Khanmy, and P. Margot, Ink aging: perspectives on standardization. Advances in Forensic Sciences, 3, 304-309 (1993).

20. Starrs, J., Ink dating up-dated and up-ended. International Journal of Forensic Document Examiners, 1(1), 3-5 (1995).

21. Margot, P., T. Hicks Champod, and A. Khanmy, Ink dating up-dated and up-ended-correspondence of Prof. Starrs. International Journal of Forensic Document Examiners, 1(1), 2-5 (1995).

22. Aginsky, V., Accelerated aging — its use in methods for dating ink. International Journal of Forensic Document Examiners, 2(3), 179-181 (1996).

23. Stewart, L. and S. Fortunato, Distinguishing between relative ink age determinations and the accelerated aging technique. International Journal of Forensic Document Examiners, 2(1), 10-15 (1996).

24. Aginsky, V.N., Measuring ink extractability as a function of age-why the relative aging approach is unreliable and why it is more correct to measure ink volatile components than dyes. International Journal of Forensic Document Examiners, 4, 214230 (1998).

25. Andermann, N. and R. Neri, Solvent extraction techniques-possibilities for dating ballpoint pen inks. International Journal of Forensic Document Examiners, 4, 231-239 (1998).

26. Weyermann, C., B. Schiffer, and P. Margot, A logical framework to ballpoint ink dating

Egypt. J. Chem. 62, No. 3 (2019) 
interpretation. Sci Justice, 48(3), 118-25 (2008).

27. Weyermann, C., et al., Photofading of ballpoint dyes studied on paper by LDI and MALDI MS. Journal of the American Society for Mass Spectrometry, 17(3), 297-306 (2006).

28. Weyermann, C., Dating: Document. Wiley Encyclopedia of Forensic Science, (2009).

29. Jahns, K., Altersbestimmung von Schreibmitteln durch Chemische Analysverfahren. Mannheimer Hefte Für Schriftvergleichung, Peter E. Baier, Universität Mannheim, Schmidt/Römhild, 29, (2004).

30. Berger-Karin, C., U. Hendriks, and GeyerLippmann, Comparison of natural and artificial aging of ballpoint inks. Journal of Forensic Sciences, 53(4), 989-992 (2008).

31. Stewart, L.F., Ballpoint ink age determination by volatile component comparison-a preliminary study. Journal of Forensic Science, 30(2), 405411 (1985)

32. Aginsky, V.N. Current methods for dating ink on documents. in Proceedings of the 60th Annual Conference of the American Society of Questioned Document Examiners, San Diego, CA, USA, (2002).

33. Andrasko, J. Ink dating using SPME and methanol extraction. in 3rd Meeting of the European Network of Forensic Science Institutes, Istanbul, (2003).

34. ,Aginsky, V.N., Dating and characterizing writing, stamp pad and jet printer inks by gas chromatography/mass spectrometry. Int. J. Forensic Doc Examiners, 2(2), 103-15 (1996).

35. ,Gaudreau, M. and L. Brazeau. Ink dating using a solvent loss ratio method. in Proceedings of the $60 t h$ Annual Conference of the American Society of Questioned Document Examiners (2002).

36. LaPorte, G.M., et al., The identification of 2-phenoxyethanol in ballpoint inks using gas chromatography/mass spectrometry-relevance to ink dating. Journal of Forensic Science, 49(1), $1-5(2003)$

37. Lociciro, S., et al., Dynamic of the aging of ballpoint pen inks: quantification of phenoxyethanol by GCMS. Science \& justice: Journal of the Forensic Science Society, 44(3), 165-171 (2004).
38. Brazeau, L. and M. Gaudreau, Ballpoint Pen Inks: The Quantitative Analysis of Ink Solvents on Paper by Solid-Phase Microextraction. Journal of Forensic Sciences, 52(1), 209-215 (2007).

39. Weyermann, C., et al., A GC/MS study of the drying of ballpoint pen ink on paper. Forensic Science International, 168(2-3), 119-127 (2007).

40. Bügler, J.H., H. Buchner, and A. Dallmayer, Age determination of ballpoint pen ink by thermal desorption and gas chromatography-mass spectrometry. Journal of Forensic Sciences, 53(4), 982-988 (2008).

41. Andrasko, J., Some examples of applications of a microthermal desorption device in the forensic laboratory. Journal of Forensic Sciences, 54(5), 1055-1058 (2009).

42. Ezcurra, M., et al., Analysis of bic crystal medium ballpoint pen inks. J. Am. Soc. Questioned Doc. Examiners, 12, 57-68 (2009).

43. Bügler, J.H., H. Buchner, and A. Dallmayer, Characterization of ballpoint pen inks by thermal desorption and gas chromatography-mass spectrometry. Journal of Forensic Science, 50(5), JFS2004486-6 (2005).

44. Weyermann, C., Mass spectrometric investigation of the aging processes of ballpoint ink for the examination of questioned documents. Universitätsbibliothek Giessen (2005).

45. Weyermann, C. and B. Spengler, The potential of artificial aging for modeling of natural aging processes of ballpoint ink. Forensic Science International, 180(1), 23-31 (2008).

46. Kikuchi, Y., Estimation of age of blue-black ink writing (III). Japanese Police Science Report, 16(1), 83-86 (1963).

47. Weyermann, C., B. Schiffer, and P. Margot, A logical framework to ballpoint ink dating interpretation. Science and Justice, 48(3), 118-125 (2008).

48. Ezcurra, M., et al., Analytical methods for dating modern writing instrument inks on paper. Forensic Science International, 197(1-3), 1-20 (2010).

(Received 11/8/2018; accepted 17/10/2018) 
تأريخ العمر الزمني لأحبار القلم الجاف باستخدام تقتية كروماتوغرافيا الغازـ مطياف الكتلة

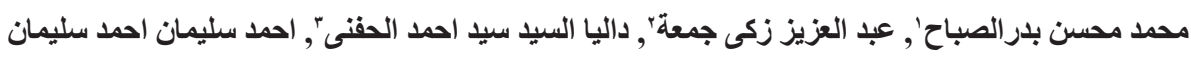

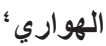
لكلية العلوم - جامعة الأزهر (بنين) ـ القاهرة - مصر.

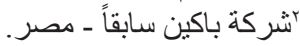

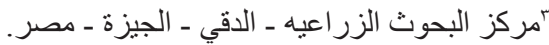
كُقطاع الطب الثرعي- وزارة العدل ـ القاهرة ـ مصر.

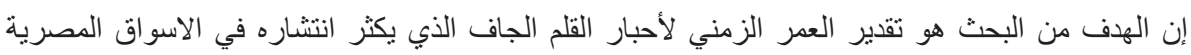

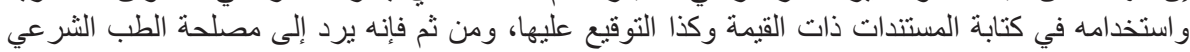

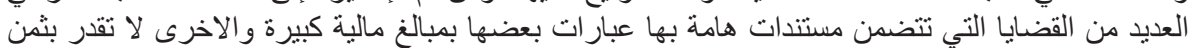

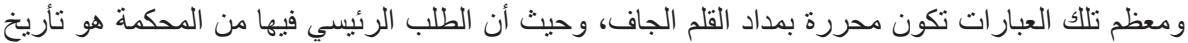

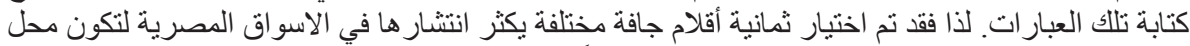

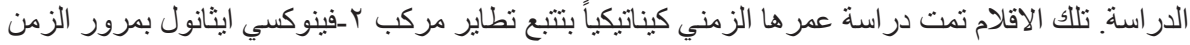

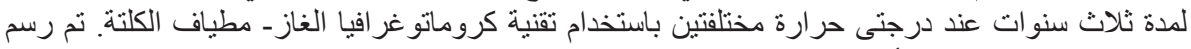

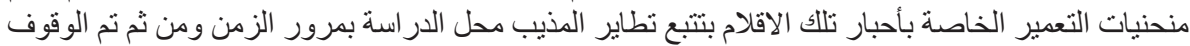

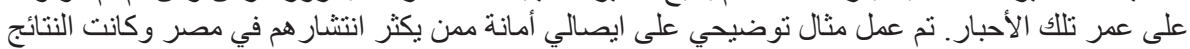

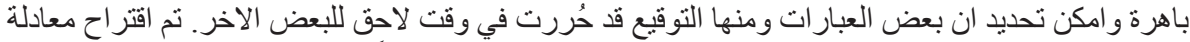
رياضية بتطبيقها يمكن توقع العمر الزمني لتأريخ المداد محل الدرأسة فئ نظرياً. 